\title{
Morphology and Properties of Hydrogenated Nitrile Rubber/Poly Hydroxyl Zinc Monomethacrylate Composites by Curing with Peroxide
}

\author{
Guanzhong Wang ${ }^{1}$, Zaifeng $\mathrm{Li}^{1 *}$, Shuaicheng Tian ${ }^{1}$, Zenglin Wang ${ }^{2}$, Baoquan Sun $^{2}$ and \\ Futao Zhang ${ }^{2}$
}

${ }^{1}$ Key Laboratory of Eco-Chemical Engineering, Ministry of Education, College of Chemistry and Molecular Engineering, Qingdao University of Science and Technology, Qingdao 266042, P.R., China

${ }^{2}$ Oil Production Institute of Shengli Oilfield, Dongying 257000, P.R., China

\begin{abstract}
The morphology evolution of hydroxyl zinc monomethacrylate (HZMMA) in hydrogenated nitrile rubber (HNBR) during its formation, and effect of synergistic behavior of HZMMA and carbon black (CB) in HNBR on its properties, were investigated. Fourier transform infrared spectroscopy (FTIR), differential scanning calorimetry (DSC), transmission electron microscopy (TEM) and X-ray diffraction (XRD) were used to probe the reaction of in-situ polymerized HZMMA. The results showed that an ionic polymer interpenetrating HNBR, due to homo-polymerization or graft polymerization of HZMMA solid monomer occurred, and poly-HZMMA particles, confirmed by FTIR and TEM, were formed during the HNBR vulcanization process. This kind of morphology for the HNBR composites played a very significant role in the HNBR reinforcement. At ambient temperature, the mechanical properties of HNBR composite filled with pure PHZMMA was much superior to those of the HNBR/PHZMMA/CB composites; however, when the temperature was increased to above $50^{\circ} \mathrm{C}$, the decrease of the tensile strength for the latter was slower, and the tensile strength was always higher than that of the HNBR composites reinforced with pure PHZMMA at the same temperature. The elongation at break above $80^{\circ} \mathrm{C}$ was also always higher than that of the HNBR/PHZMMA sample. The HNBR/PHZMMA/CB composites showed excellent air oven aging resistance.
\end{abstract}

Keywords: hydrogenated nitrile rubber, hydroxyl zinc monomethacrylate, morphology, properties

\section{INTRODUCTION}

Recently many oil wells are at the high cut-off stage. The drilling condition of new wells becomes worse annually. In addition, new drilling methods have been adopted. Current packer rubber tubes used for sealing, which can withstand up to $120^{\circ} \mathrm{C}$, cannot satisfy the need of current oil-gas well drilling. In general, the main upper limit specification standard for rubber tubes has been listed as working normally at $150^{\circ} \mathrm{C}$ and a pressure difference of $30 \mathrm{MPa}$. However, for hydraulic fracturing wells, the temperature requirement of the rubber tubes is usually about $150{ }^{\circ} \mathrm{C}$, sometimes, on special occasion even rises to $180^{\circ} \mathrm{C}$. Thus, it is necessary to develop a new rubber composed material for the drilling of oil wells. HNBR has been used for the packer rubber tubes in the past and many reports about improving its mechanical properties by forming composites have been published [1-5].

In recent years, HNBR composites enhanced by zinc dimethacrylate (ZDMA) have attracted widespread attention. In practice, there are generally two methods of reinforcing rubber by zinc dimethacrylate, both

\footnotetext{
*Address correspondence to this author at the Key Laboratory of Eco-chemical Engineering, Ministry of Education, College of Chemistry and Molecular Engineering, Qingdao University of Science and Technology, Qingdao 266042, P.R., China; Tel: +86-0532-84023757; Fax: +86-0532-84022918;

E-mail: lizfengphd@126.com
}

domestically and abroad. One is adding zinc dimethacrylate prepared in advance to reinforce the rubber [6-8]. The other is adoption of an in-situ reaction from methacrylic acid and zinc oxide, thus generating in-situ zinc dimethacrylate during the mixing process [9-11]. The above reported results showed that the zinc dimethacrylate had an excellent reinforcing effect. However, the high temperature mechanical properties requirements of the composite were still not satisfied.

In this paper the synergistic behavior of hydroxyl zinc mono-methacrylate (HZMMA) instead of zinc dimethacrylate (ZDMA) and carbon black was investigated. The research focused on the chemical reaction between HZMMA and the polymer matrix. It was expected to fabricate a more durable rubber composite material which could be used at higher temperatures and under higher pressures.

\section{EXPERIMENTAL}

\section{Materials}

Hydrogenated nitrile rubber (HNBR) (2010), having $36 \%$ acrylonitrile content and $4 \%$ residual double bonds, was provided by Nippon Zeon Co., Ltd. (Japan). This rubber exhibited a Mooney viscosity ML $(1+4)$ $100^{\circ} \mathrm{C}=85$. Hydroxyl zinc monomethacrylate (HZMMA), which has single methyl and carbonyl groups was 
supplied by Sartomer Co., Inc. (USA). Carbon black (N220) with average particle size of $23 \mathrm{~nm}$ and CTAB surface area of $115 \mathrm{~m}^{2} / \mathrm{g}$ was supplied by Degussa AG (Germany). The other rubber additives were commercial grades.

\section{Preparation of HNBR/PHZMMA/CB Composites}

The mixing of the rubber with the compounding system was conducted in an open two $15.24 \mathrm{~cm}$ (6in) roll mill (produced by Shanghai Rubber Machinery Works No.1, China) with the conventional mixing technique. Note that the additives $\mathrm{ZnO}$, stearic acid, triallyl isocyanurate (TAIC), and antioxidant were gradually added into the kneader, after several mixing cycles, and then the carbon black and HZMMA were added, finally initiator dicumyl peroxide (DCP) was added. The composites were sheeted out 10 times on the two-roll mill to get $3 \mathrm{~mm}$ to $5 \mathrm{~mm}$ thickness sheets. The obtained composites were finally compression cured at $170^{\circ} \mathrm{C}$ for 15 min under $10 \mathrm{MPa}$ into sheets of suitable thickness. All samples were preconditioned at $23^{\circ} \mathrm{C}$ for $24 \mathrm{~h}$ before being tested.

The model HNBR composite filled with HZMMA and DCP only was used to test the morphology evolution of HZMMA during the HNBR process.

The compounds in our experiments contain $100 \mathrm{phr}$ HNBR, 1 phr SA, 5 phr ZnO, 1.5 phr antioxidants, 2 phr TAIC, 5 phr DCP, various loading of ZDMA/ CB.

\section{Characterization}

The crystal structure change of HZMMA was studied by $X$-ray diffraction (XRD) in transmission mode using Ni-filtered $\mathrm{Cu}$ Ka radiation $(\lambda=0.1542 \mathrm{~nm})$ by a D-MAX 2500/PC (Rigaku, Japan). The samples were scanned in step mode $(1 \% \mathrm{~min})$ in the range of $2 \theta$ from $2^{\circ}$ up to $20^{\circ}$. The XRD spectra of the HZMMA powders were also recorded.

The reaction of HZMMA in the rubber matrix was tested by In-situ FTIR. The HZMMA particles were ground with $\mathrm{KBr}$ powder and the mixture was pressed into pellets for FTIR measurements. The specimen was placed in an electrically heated sample holder. FTIR spectra were recorded at a resolution of $2 \mathrm{~cm}^{-1}$ with a DTGS detector on a Bruker TENSOR 27 FTIR spectrometer (Germany). The samples, which were heated at $2^{\circ} \mathrm{C} / \mathrm{min}$, were scanned from $30^{\circ} \mathrm{C}$ to $250^{\circ} \mathrm{C}$.

Tensile and tear tests were performed on a Gotech Al-7000M (China) universal testing machine at a cross- head speed of $500 \mathrm{~mm} \cdot \mathrm{min}^{-1}$. The tensile specimens were tested according to DIN 53504 while an angle test piece (DIN ISO 34-1) was used for the tear tests. The tensile value represents the average of five parallel tests, while the tear resistance was derived from three parallel tests.

A Netzsch (Germany) DSC 204F1 was used for DSC. About $10 \mathrm{mg}$ of sample were heated at $10 \mathrm{~K} / \mathrm{min}$ from $30^{\circ} \mathrm{C}$ to $250^{\circ} \mathrm{C}$ in nitrogen.

Transmission electron microscopy (TEM) observations were performed on a JSM-7100F transmission electron microscope (JEOL, Japan) with an acceleration voltage of $160 \mathrm{kV}$. The ultra-thin sections of samples for TEM observations were cut by a microtome at under $-100^{\circ} \mathrm{C}$.

\section{RESULTS AND DISCUSSION}

\section{Tracking of the Reaction Heat of Hydroxyl Zinc Monomethacrylate}

Figure 1 shows the DSC curves of HZMMA and the mixture of HZMMA with initiator agent DCP. For the HZMMA, with increasing temperature, a melting endothermic peak was observed at about $155^{\circ} \mathrm{C}$ due to melting of the HZMMA crystals, and then a weak exothermic peak attributed to the polymerization reaction of $\mathrm{HZMMA}$ occurred at about $165^{\circ} \mathrm{C}$. However, in the DSC curve of the mixture of HZMMA with initiating agent DCP, a eak endothermic peak associated with the melting of the initiator DCP appeared at about $45^{\circ} \mathrm{C}$. When the temperature approached about $120^{\circ} \mathrm{C}$, the little initiator began to decompose and the radical sites were appeared, they immediately initiated the radical polymerization of HZMMA to produce reaction heat. Because of the

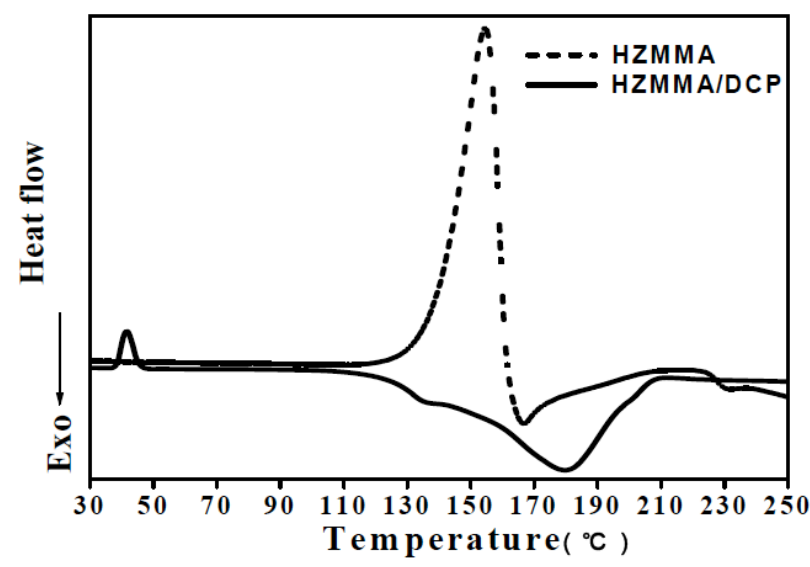

Figure 1: DSC curves of HZMMA and HZMMA mixed with initiator DCP. 
<smiles></smiles>

cancellation of the endothermic decomposition reaction heat of the initiator by the exothermic reaction heat for radical polymerization of $\mathrm{HZMMA}$, in the range of $120^{\circ} \mathrm{C}$ up to $210^{\circ} \mathrm{C}$, only a wide and weak exothermic peak attributed to the polymerization of HZMMA was observed. The maximum of the exothermic peak appeared around $180^{\circ} \mathrm{C}$.

Figure 2 shows selected in situ FTIR spectra changes for HZMMA with an increase in temperature. The absorption bands at $3610 \mathrm{~cm}^{-1}$ and $658 \mathrm{~cm}^{-1}$ are assigned to the stretching mode and out-of-plane deformation mode of $\mathrm{Zn}-\mathrm{OH}$, respectively. With an increase in temperature, the intensities of $3610 \mathrm{~cm}^{-1}$ and $658 \mathrm{~cm}^{-1}$ both decreased synchronously, indicating the decrease of $\mathrm{Zn}-\mathrm{OH}$ groups. The stretching vibration absorption of the hydroxyl groups declined greatly at $125^{\circ} \mathrm{C}$ and disappeared at $210^{\circ} \mathrm{C}$, which revealed that dehydration happened during the heating process. The development of $\mathrm{Zn}-\mathrm{O}-\mathrm{Zn}$ structure above $120^{\circ} \mathrm{C}$ can be confirmed based on the band at $1205 \mathrm{~cm}^{-1}$. In view of the above experimental results, the possible dehydration reaction equation was as follow.
In Figure 3, showing other portions of the HZMMA spectra, the band at $1643 \mathrm{~cm}^{-1}$ is attributed to the vibration of $\mathrm{CH}_{2}=\mathrm{C}$ - groups, the bands at $934 \mathrm{~cm}^{-1}$ and $811 \mathrm{~cm}^{-1}$ are attributed to the out-of-plane bending vibration of $\mathrm{C}-\mathrm{H}$ on $\mathrm{H}_{2} \mathrm{C}=\mathrm{C}$. With increasing temperature, their absorbance intensities decreased. When the temperature was above $210^{\circ} \mathrm{C}$, because of the completion of the reactions of the $\mathrm{CH}_{2}=\mathrm{C}$ - groups, the band at $1643 \mathrm{~cm}^{-1}$ for $\mathrm{CH}_{2}=\mathrm{C}$ - groups unchanged. It was concluded that the radical polymerization of $\mathrm{CH}_{2}=\mathrm{C}$ - groups of HZMMA monomer molecule occurred from 125 to $210^{\circ} \mathrm{C}$.

\section{Probe of Crystal Structure Change of HZMMA Curing with Peroxide}

Figure 4 shows the XRD spectra of the HZMMA crystalline powder, and the HZMMA and mixture of HZMMA and DCP after being heated at $170{ }^{\circ} \mathrm{C}$ for $1 \mathrm{~h}$. In the scan curve (a), clear diffraction peaks of HZMMA at $4.68^{\circ}, 7.38^{\circ}$, and $8.56^{\circ}(2 \theta)$ were observed. When the HZMMA was treated for $1 \mathrm{~h}$ at $170^{\circ} \mathrm{C}$, these diffraction peaks disappeared due to the change of the

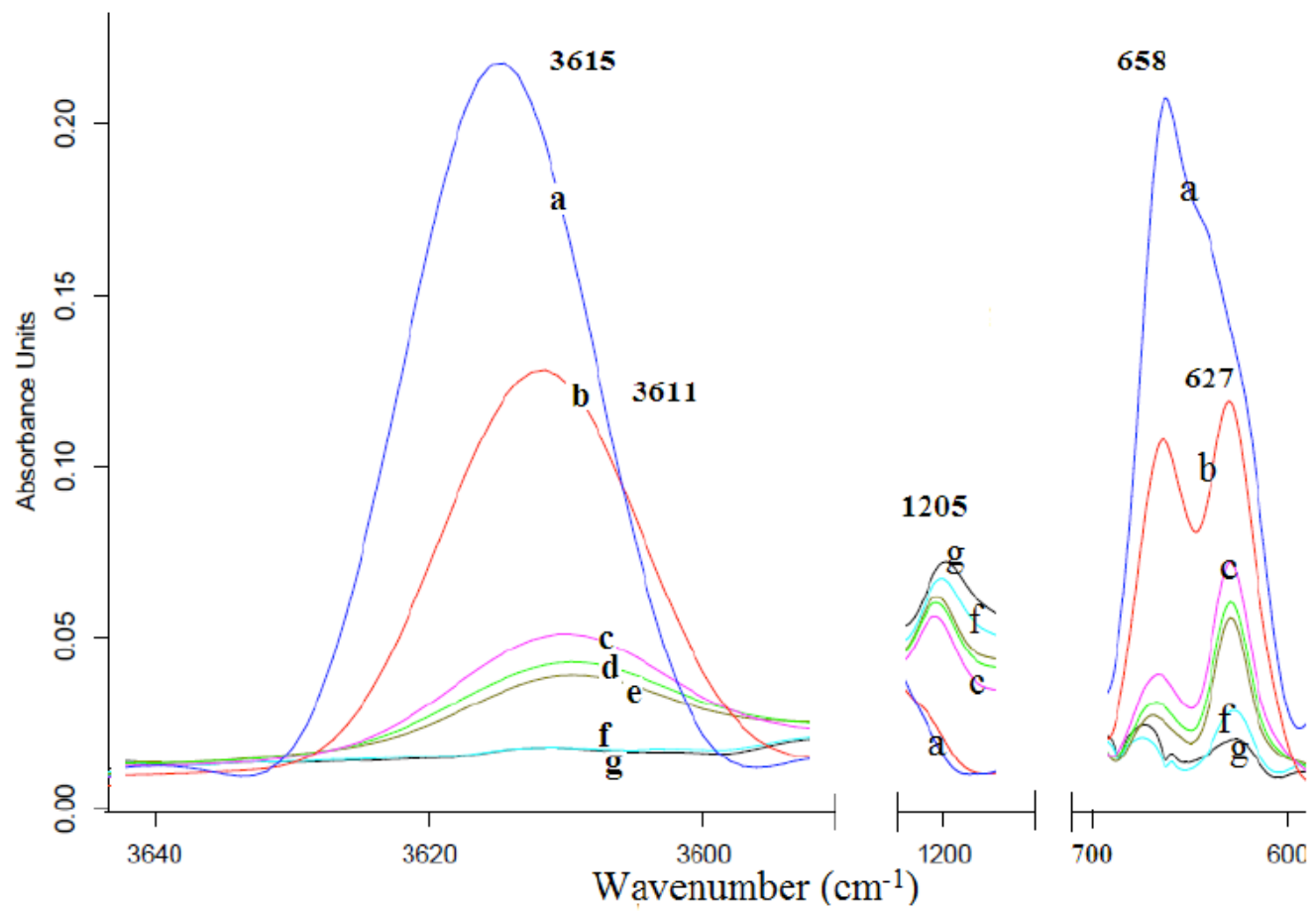

Figure 2: Selected temperature-dependent FTIR spectra for feature function groups of HZMMA.

(a) $30^{\circ} \mathrm{C}$, (b) $125^{\circ} \mathrm{C}$, (c) $154^{\circ} \mathrm{C}$, (d) $160^{\circ} \mathrm{C}$, (e) $166^{\circ} \mathrm{C}$, (f) $210^{\circ} \mathrm{C}$, (g) $250^{\circ} \mathrm{C}$. 


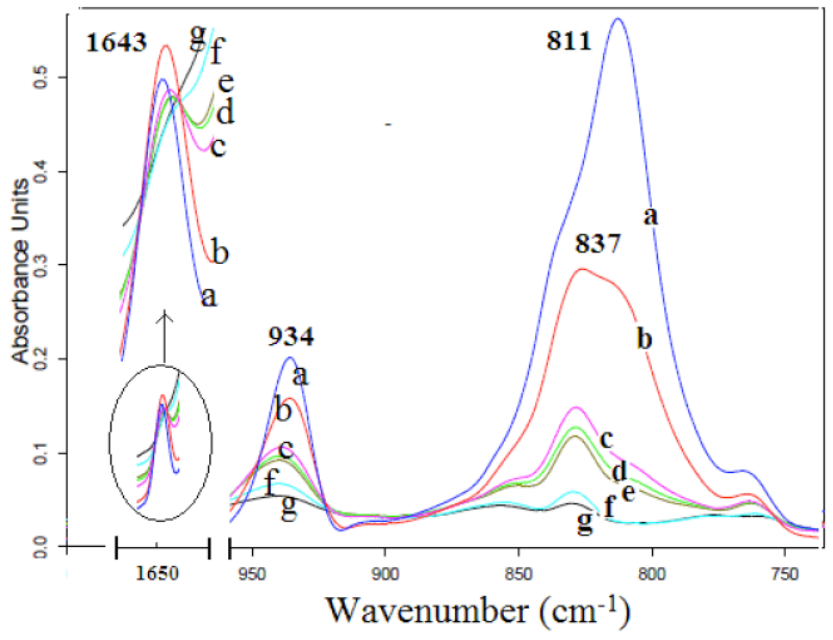

Figure 3: Selected temperature-dependent FTIR spectra for HZMMA from $750 \mathrm{~cm}^{-1}$ to $1650 \mathrm{~cm}^{-1}$.
(a) $30^{\circ} \mathrm{C}$, (b) $125^{\circ} \mathrm{C}$
(c) $154^{\circ} \mathrm{C}$
(d) $160^{\circ} \mathrm{C}$
(e) $166^{\circ} \mathrm{C},(\mathbf{f})$ $210^{\circ} \mathrm{C},(\mathbf{g}) 250^{\circ} \mathrm{C}$.

perfect crystalline structure in the scan (c), new crystalline diffraction peaks at $9.88^{\circ}$ and $10.86^{\circ}(2 \theta)$ were observed. In the XRD scan (b) for the mixture of HZMMA and DCP, treated at $170{ }^{\circ} \mathrm{C}$ for $1 \mathrm{~h}$, all the diffraction peaks of the crystalline structure of HZMMA disappeared. It was concluded that disappearance of all diffraction peaks of HZMMA was associated with the polymerization reaction of the $\mathrm{CH}_{2}=\mathrm{C}$ - groups forming PHZMMA, These XRD results were consistent with the conclusion from FTIR data.

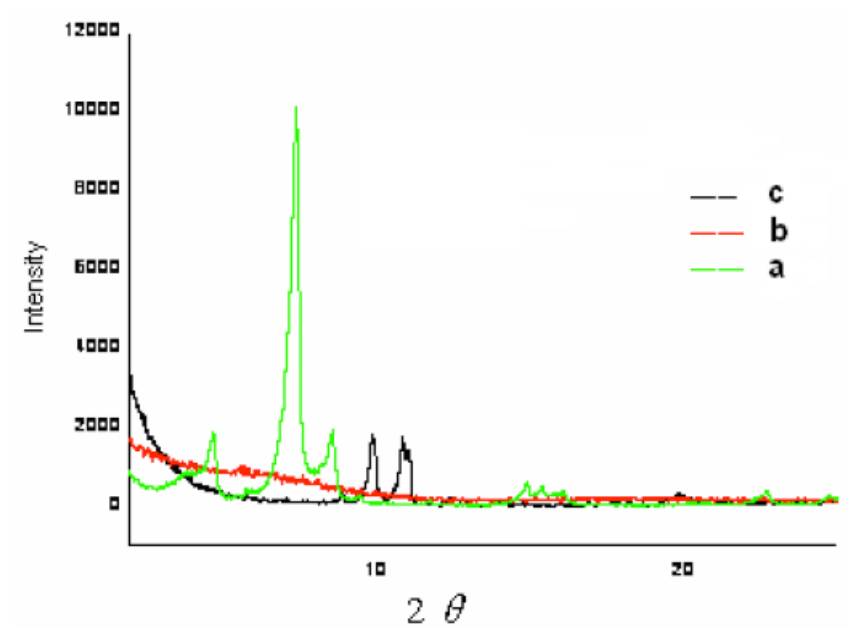

Figure 4: XRD spectra of HZMMA and HZMMA/DCP.

(a) HZMMA, (b) HZMMA/DCP after being heated at $170{ }^{\circ} \mathrm{C}$ for $1 \mathrm{~h}$, (c) HZMMA after being heated at $170^{\circ} \mathrm{C}$ for $1 \mathrm{~h}$.

\section{The Morphology Evolution of HZMMA in an HNBR Matrix}

The morphology of the HNBR/PHZMMA compound before vulcanizing is shown in Figure 5a. HZMMA crystalline solids were dispersed uniformly in the HNBR matrix, but the size of the HZMMA was not uniform; they consisted both of long ribbons and little needle crystals. After the curing process at $170^{\circ} \mathrm{C}$, owing to the radical polymerization of $\mathrm{CH}_{2}=\mathrm{C}$ - groups of $\mathrm{HZMMA}$ monomer molecule occurred in the HNBR composite, crystalline solids consist of HZMMA monomer became the poly-HZMMA particles, with micro-scale size of about 20 50nm, were dispersed evenly in the HNBR [12-14], as shown in Figure $\mathbf{5 b}$.
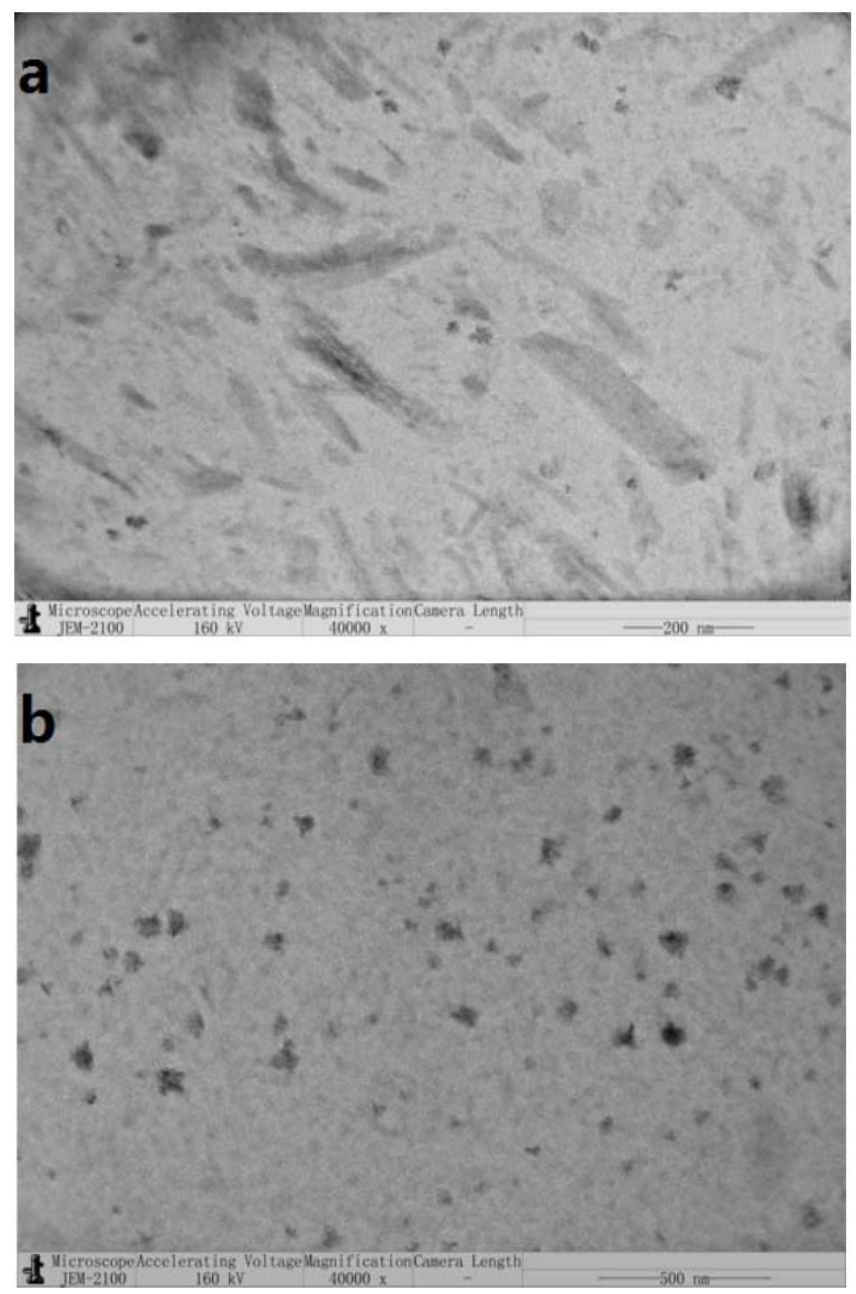

Figure 5: TEM images of HNBR/HZMMA composites before (a) and after (b) the vulcanizing process.

The in-homogeneity of the polymerization resulted in the poly-HZMMA particles dispersed in HNBR having different sizes. The HNBR composites were reinforced by the poly-HZMMA ionic polymer, and the tensile strength of HNBR composite filled with HZMMA could reach about $50.0 \mathrm{MPa}$ (see below). Another important factor in rubber-reinforcing by HZMMA is the graft polymerization between HNBR and HZMMA, which increased the interaction of the two kinds of material [15]. The proposed reaction equations are as follows. 


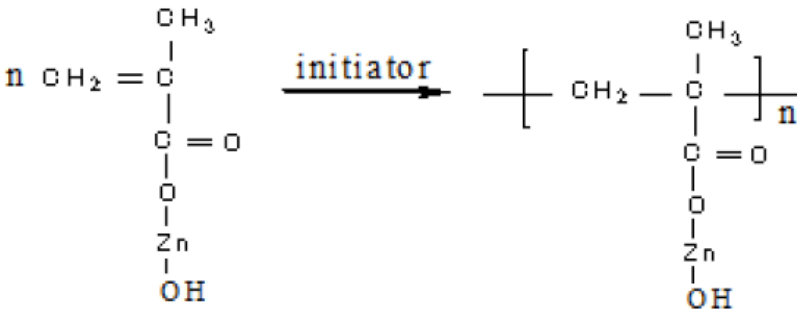

$$
\begin{aligned}
& \text { HZMMA }
\end{aligned}
$$

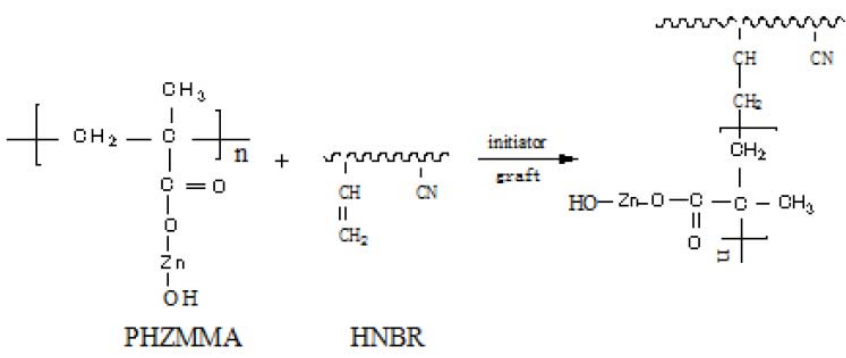

Comparison of the Mechanical Properties before and After Aging

As shown in Table 1, the tensile strength of HNBR filled by PHZMMA and $C B$ were considerably lower than that of HNBR filled by PHZMMA only before aging. The tensile strength of HNBR filled with $50 \mathrm{phr}$ pure PHZMMA was around $50.0 \mathrm{MPa}$ at room temperature, and the sample also had a larger tensile set and elongation at break than those filled with HZMMA and CB. The strong matrix-filler interaction of HNBR with the PHZMMA particles and the ionic bonds in this HNBR/PHZMMA compound were responsible for the observed reinforcing effect. The presence of carbon black in HNBR/PHZMMA/CB rubber composite relatively reduced the phy-chem interaction between HNBR and PHZMMA, but it increased the effect of physical crosslink, therefore, HNBR/PHZMMA/CB rubber composite showed the lower tensile strength, elongation at break and Permanent set.

After $150^{\circ} \mathrm{C} \times 72 \mathrm{~h}$, the results indicated that aging process resulted in an increase in hardness of the samples, but a major decrease in mechanical properties. The PHZMMA filler alone resulted in worse rubber aging-resistance than the PHZMMA/CB composites, although they had lower values than before aging. The best aging-resistance performance for the four samples was attributed to the mass ratio of 30/20 for the PHZMMA and CB. It was seen that after aging, the tensile strength retention for the HNBR with PHZMMA and CB was $95 \%$, while the tensile strength retention for the HNBR with pure PHZMMA filler was only $50 \%$. Thus, it was concluded that the HNBR composite filled with PHZMMA/CB mixture at a 30/20 ratio showed the better aging-resistance performance and the highest residual tensile strength.

\section{Effect of Temperature on the Mechanical Properties}

Although the HNBR composites had excellent mechanical properties at room temperature, as rubber composites for packer tubes used in oil field, it was

\begin{tabular}{|c|c|c|c|c|c|}
\hline \multirow{2}{*}{ Specimen } & \multicolumn{4}{|c|}{ PHZMMA/Carbon Black (phr) } & \multirow[b]{2}{*}{$0 / 50$} \\
\hline & $50 / 0$ & $40 / 10$ & $30 / 20$ & $20 / 30$ & \\
\hline \multicolumn{6}{|c|}{ Before Aging } \\
\hline Hardness(Shore A) & 85 & 82 & 84 & 84 & 83 \\
\hline Tensile strength (MPa) & 50.0 & 40.0 & 42.9 & 40.1 & 32.7 \\
\hline Tensile strength $100 \%(\mathrm{MPa})$ & 9.8 & 8.1 & 7.3 & 6.4 & 5.0 \\
\hline Elongation at break (\%) & 381 & 297 & 298 & 239 & 230 \\
\hline Permanent set (\%) & 25 & 15 & 15 & 15 & 15 \\
\hline \multicolumn{6}{|c|}{ After Aging $\left(150^{\circ} \mathrm{C} \times 72 \mathrm{~h}\right)$} \\
\hline Hardness (Shore A) & 89 & 83 & 85 & 90 & 90 \\
\hline Tensile strength (MPa) & 25.8 & 37.6 & 40.4 & 36.7 & 30.1 \\
\hline Tensile strength $100 \%$ (MPa) & 10.1 & 9.5 & 9.6 & 10.2 & 11.0 \\
\hline Elongation at break (\%) & 280 & 225 & 210 & 170 & 172 \\
\hline Permanent set (\%) & 15 & 12.5 & 10 & 10 & 10 \\
\hline Tensile retention (\%) & 52 & 94 & 95 & 92 & 92 \\
\hline
\end{tabular}

Table 1: Comparison of the Mechanical Properties for HNBR Composites with Different Relative Content of PHZMMA/CB before and after Aging 

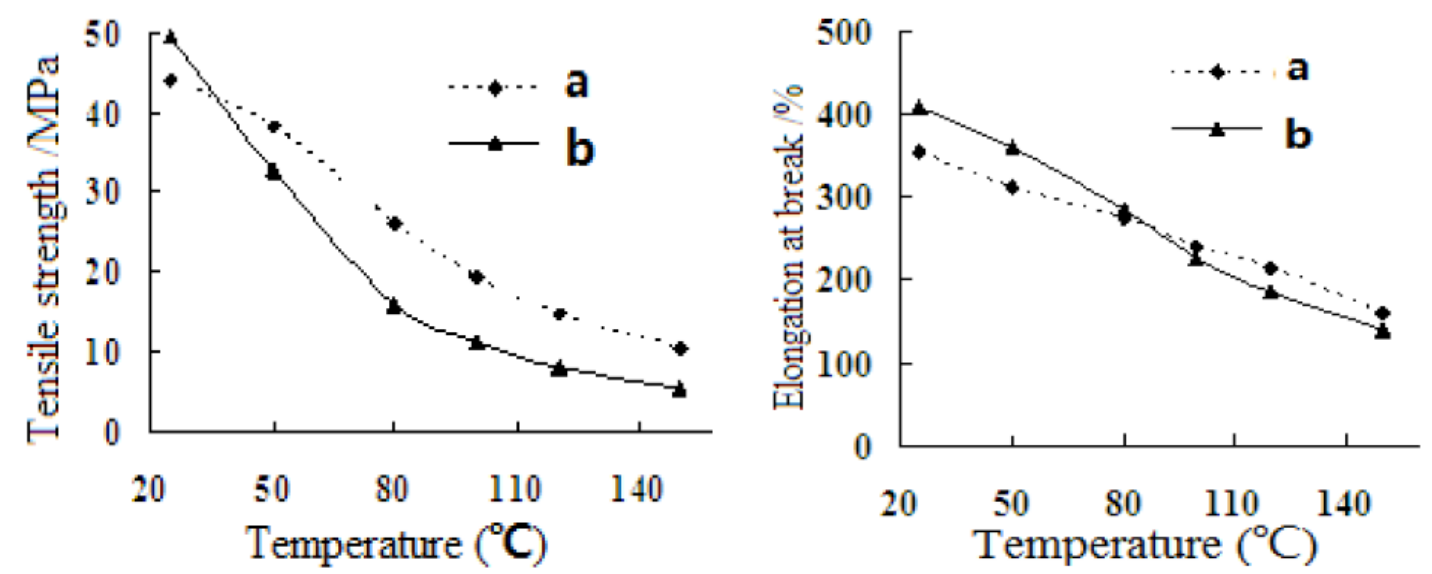

Figure 6: Effect of temperature on the mechanical properties of HNBR composites.

(a) PHZMMA/CB (30/20), (b) PHZMMA/CB (50/0).

necessary to study the effect of temperature on the mechanical properties of HNBR composites filled with PHZMMA or PHZMMA/CB. Compared temperaturedependent tensile strength and elongation at break for HNBR rubber filled by pure PHZMMA were shown in Figure 6. Although the $\mathrm{PHZMMA} / \mathrm{CB}$ filled rubber composite showed a lower tensile strength and a lower elongation at break at room temperature, however, it showed a higher tensile strength and elongation at break when the testing temperature was increased. Even at $150^{\circ} \mathrm{C}$, the HNBR/PHZMMA/CB composites still showed excellent mechanical properties, its tensile strength even reached up to $12 \mathrm{MPa}$. The value is equal to the maximum tensile strength of fluorinated silicone rubber at room temperature.

\section{CONCLUSIONS}

Based on tracking of the reaction heat of HZMMA, the XRD observed crystalline structure change of HZMMA, the morphology evolution of HZMMA in an HNBR matrix and the temperature-dependent FTIR spectra for HZMMA, it is concluded that an ionic polymer (PHZMMA) was formed from the radical polymerization of HZMMA, a grafted structure was also present between PHZMMA and HNBR. This kind of unique polymer alloy structure made the HNBR composites show superior mechanical properties and thermal stability. The poly-HZMMA particles resulting from the homo-polymerization showed excellent reinforcing performance in the HNBR. By means of FTIR spectroscopy, the course of possible reactions of HZMMA during heating was traced, and a $\mathrm{Zn}-\mathrm{O}-\mathrm{Zn}$ backbone structure was formed between HZMMA molecules. This characteristic was reflected by the super mechanical performance. Compared with pure PHZMMA reinforcement, although the PHZMMA/CB reinforcing system showed lower tensile strength at room temperature, the PHZMMA/CB reinforced HNBR composites retained excellent aging-resistance performance and tensile strength at high temperature.

\section{ACKNOWLEDGEMENTS}

This research work was funded by the AustraliaChina Natural Gas Technology Partnership Fund, Shandong provincial nature science fund (ZR2013EMM007), Qingdao science and technology project (13-1-4-147-jch) and National Natural Science Foundation of China (Grant No. 21176126).

\section{REFERENCES}

[1] Kousei H, Ken S, Kenji N, Masatoshi T. Phase separation structure in the polymer blend of fluorocarbon elastomer and hydrogenated nitrile rubber. J Appl Polym Sci 2005; 95: 14956.

http://dx.doi.org/10.1002/app.20804

[2] Felhos D, Karger-Kocsis J, Xu D. Tribological testing of peroxide cured HNBR with different MWCNT and silica contents under dry sliding and rolling conditions against steel. J Appl Polym Sci 2008; 108: 2840-51. http://dx.doi.org/10.1002/app.27624

[3] Gatos KG, Sawanis NS, Apostolov AA, Thomann R, KargerKocsis J. Nanocomposite formation in hydrogenated nitrile rubber (HNBR)/organo-montmorillonite as a funtion of the intercalant type. Macromol Mater Eng 2004; 289: 1079-86. http://dx.doi.org/10.1002/mame.200400214

[4] Gatos KG, Szazdi L, Pukanszky B, Karger-Kocsis J. Controlling the deintercalation in hydrogenated nitrile rubber (HNBR)/organo-montmorillonite nanocomposites by curing with peroxide. Macromo Rapid Comm 2005; 26: 915-9. http://dx.doi.org/10.1002/marc.200500084

[5] Zheng W, Lu YL, Meng Y, Zhang LQ. Study on wear, cutting and chipping behaviors of hydrogenated nitrile butadiene rubber reinforced by carbon black and in situ prepared zinc dimethacrylate. Appl Polym Sci 2012; 124: 4564-71.

[6] Li Q, Zhao SH, Zhu LL. Structure and properties of HNBR filled with ZDMA/silica. China Rubber Ind 2010; 2: 69-75. 
[7] Li Q, Zhao SH, Pan Y. Structure, morphology, and properties of HNBR filled with $\mathrm{N550}, \mathrm{SiO}_{2}, \mathrm{ZDMA}$, and two of three kinds of fillers. J Appl Polym Sci 2010; 117: 421-7. http://dx.doi.org/10.1002/app.31744

[8] Chae HD, Basuli U, Lee JH, et al. Mechanical and thermal properties of rubber composites reinforced by zinc methacrylate and carbon black. Polym Compos 2012; 33: 1141-53. http://dx.doi.org/10.1002/pc.22242

[9] Zhao XB, Zhang QY, Gu JW, Yin DZ, Yin CJ. Effects of carbon black on the properties of HNBR reinforced by in situ prepared ZDMA. Polym-Plast Technol 2011; 50: 1507-10. http://dx.doi.org/10.1080/03602559.2011.593086

[10] Chen YK, Wang XP, Jia DM. Structure and properties of in situ generated zinc methacrylate reinforced natural rubber. China Synth Rubber Ind 2005; 28: 288-92.

[11] Zhao XB, Zhang QY, Yin DZ, Gu JW, Yin CJ. Structure and properties of HNBR/PZDMA nanocomposites prepared by insitu polymerization. Modern Chem Ind 2011; 12: 32-5.
[12] Zheng W, Lu YL, Yan SK, Meng Y, Zhang LQ. Dramatic influence of curing temperature on micro-nano structure transform of HNBR filled with zinc dimethacrylate. Appl Polym Sci 2012; 124: 288-95.

http://dx.doi.org/10.1002/app.34615

[13] Lu YL, Liu L, Yang C, Tian M, Zhang LQ. The morphology of zinc dimethacrylate reinforced elastomers investigated by SEM and TEM. Eur Polym 2005; 41: 577-88. http://dx.doi.org/10.1016/i.eurpolymj.2004.10.019

[14] Lu YL, Liu L, Shen DY, Yang C, Zhang LQ. Infrared study on in situ polymerization of zinc dimethacrylate in poly $(\alpha-$ octylene-co-ethylene) elastomer. Polym Int 2004; 53: 802-8. http://dx.doi.org/10.1002/pi.1462

[15] Ikeda T, Yamada B, Tsuji M, Sakurai S. In situ copolymerization behaviour of zinc dimethacrylate and 2-(Nethylperfluoro-octanesulphonamido) ethyl acrylate in hydrogenated nitrile-butadiene rubber during peroxide cross linking. Polym Int 1999; 48: 446-54.

http://dx.doi.org/10.1002/(SICl)1097-

0126(199906)48:6<446::AID-PI159>3.0.CO;2-9 